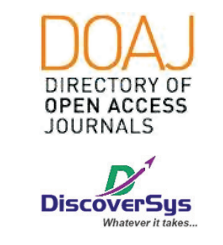

Published by DiscoverSys

\section{Hubungan dan titik potong skor Caprini terhadap D-dimer sebagai parameter resiko trombosis vena dalam pada pasien paska fiksasi internal fraktur tulang panjang ekstremitas bawah}

\author{
Made Wirabhawa, ${ }^{1 *}$ Ketut Siki Kawiyana, ${ }^{2}$ I Ketut Suyasa ${ }^{2}$ \\ Putu Astawa, ${ }^{2}$ Ketut Gede Mulyadi Ridia, ${ }^{2}$ I Wayan Suryanto Dusak, ${ }^{2}$ \\ I Gede Eka Wiratnaya, ${ }^{2}$ Anak Agung Wiradewi Lestari, ${ }^{3}$
}

\section{ABSTRACT}

Background: Fractures contribute to a substantial proportion of the emergency department cases. Surgical procedures such as internal fixation of lower limb fractures posed a risk to develop deep vein thrombosis (DVT). The current diagnosis of DVT is still a challenge, as the current main parameter, the D-dimer, requires additional laboratory time and cost. Threrefore, an easier and faster alternative should be used in clinical decision making. Caprini score is among a simple method to assess the risk of a DVT, but validation is still needed before it can be implemented.

Methods: This is an cross-sectional analytic study aimed to determine the relationship between Caprini scores and D-dimer level in patients with post-internal fixation of long bone fractures in lower extrimities at Sanglah Hospital Denpasar. Caprini scores were determined before surgery then D-dimer measurements were taken postoperatively. Statistical analysis was performed using the Pearson correlation method and ROC curve were generated to determine the cut-off point of Caprini Score equivalent of high risk DVT with the D-dimer as the predictor.

Result: The average Caprini score was 9.37 (7-13). Mean preoperative D-dimer was $6.59 \mu \mathrm{g} / \mathrm{ml}(2.50-13.20 \mu \mathrm{g} / \mathrm{ml})$, postoperatively $11.50 \mu \mathrm{g} / \mathrm{ml}(3.71-19.89 \mu \mathrm{g} / \mathrm{ml})$ and mean delta D -Dimer $5.23 \mu \mathrm{g} / \mathrm{ml}$ $(0.56-12.28 \mu \mathrm{g} / \mathrm{ml})$. Pearson correlation test obtained a strong positive relationship ( $r=0.726$ and $p \leq 0,0001)$. Analysis of the ROC curve to determine the cut-off point for Caprini score which equivalent to the high risk of DVT from D-dimer prediction ( $>7.2 \mu \mathrm{g} / \mathrm{ml}$ ) resulted in AUC of 0.824 (95\% Cl 0.669-0.979, $p=0.024)$ with the optimal cut-off point for Caprini score was 8.

Conclusion: Caprini and D-dimer scores show a strong positive correlation. Caprini scores can be considered to estimate the risk of DVT in post-internal fixation patients of lower extremities long bone fractures.

Keywords: Caprini score, D-dimer, Internal Fixation, Long Bone Fractures, DVT

Cite This Article:Wirabhawa, M., Kawiyana, K.S., Suyasa, I.K. 2020. Hubungan dan titik potong skor Caprini terhadap D-dimer sebagai parameter resiko trombosis vena dalam pada pasien paska fiksasi internal fraktur tulang panjang ekstremitas bawah. Intisari Sains Medis 11(1): 291-295. D0l: 10.15562/ism.v11i1.555

'Program Studi Orthopaedi dan Traumatologi, Fakultas Kedokteran, Universitas Udayana, Bali, Indonesia

${ }^{2}$ Departemen Orthopaedi dan Traumatologi, Fakultas Kedokteran, Universitas Udayana/ RSUP Sanglah Denpasar, Bali, Indonesia

${ }^{3}$ Departemen Patologi Klinik, Fakultas Kedokteran, Universitas Udayana/RSUP Sanglah Denpasar, Bali, Indonesia

*Korespondensi: Made Wirabhawa, Program Studi Orthopaedi dan Traumatologi Universitas Udayana. wrborthop@gmail.com

Diterima: 28-06-2019 Disetujui: $16-03-2020$ Diterbitkan: 01-04-2020

\title{
ABSTRAK
}

Latar Belakang: Kejadian fraktur memiliki proporsi yang substansial dari total pasien yang datang ke unit gawat darurat rumah sakit. Prosedur operasi seperti pemasangan fiksasi internal pada fraktur ekstremitas bawah memiliki resiko untuk terjadinya trombosis vena dalam (DVT). Penegakan diagnosis DVT saat ini masih merupakan suatu tantangan salah satunya karena pemeriksaan laboratorium D-dimer membutuhkan waktu dan biaya tambahan, sehingga dibutuhkan alternatif yang lebih mudah dan cepat digunakan dalam pengambilan keputusan klinis. Skor Caprini merupakan salah satu cara untuk menilai resiko terjadinya suatu DVT, akan tetapi masih diperlukan validasi sebelum dapat diimplementasikan.

Metode: Penelitian cross-sectional analitik dilakukan untuk mengetahui hubungan Skor Caprini dengan kadar D-dimer pada pasien paska operasi fiksasi internal fraktur tulang panjang ekstremitas bawah di RSUP Sanglah Denpasar. Skor Caprini ditentuakan sebelum operasi kemudian pengukuran D-dimer dilakukan paska operasi. Analisis statistik dilakukan dengan metode korelasi Pearson dan penentan titik potong risiko DVT dengan prediktor D-dimer menggunakan metode kurva ROC.

Hasil: Rerata Skor Caprini adalah 9,37 dengan rentang skor 7-13. Rerata D-dimer sebelum operasi sebesar 6,59 $\mu \mathrm{g} / \mathrm{ml}(2,50-13,20 \mu \mathrm{g} / \mathrm{ml})$, paska operasi $11,50 \mu \mathrm{g} / \mathrm{ml}(3,71-19,89 \mu \mathrm{g} / \mathrm{ml})$ dan rerata delta

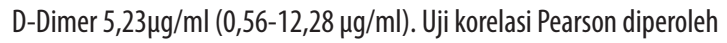
hubungan positif kuat antara Skor Caprini dengan kadar D-dimer (nilai $r=0,726$ dan nilai $p \leq 0,0001)$. Analisis kurva ROC untuk menentukan itik potong Skor Caprini yang setara dengan resiko tinggi terjadinya DVT dari prediksi D-dimer ( $>7,2 \mu \mathrm{g} / \mathrm{ml}$ ) memperoleh Area Under Curve $0,824$ (95\% Cl 0,669-0,979, $p=0,024)$ dengan titik potong optimal skor Caprini 8.

Kesimpulan: Skor Caprini dan D-dimer menunjukkan korelasi positif yang kuat pada pasien paska fiksasi internal fraktur tulang panjang ekstremitas bawah. Skor Caprini dapat dipertimbangkan sebagai acuan dalam menentukan resiko terjadinya DVT. 
Kata Kunci: Skor Caprini, D-Dimer, Fiksasi internal, Fraktur Tulang Panjang, DVT

Cite Pasal Ini: Wirabhawa, M., Kawiyana, K.S., Suyasa, I.K. 2020. Hubungan dan titik potong skor Caprini terhadap D-dimer sebagai parameter resiko trombosis vena dalam pada pasien paska fiksasi internal fraktur tulang panjang ekstremitas bawah. Intisari Sains Medis 11(1): $291-295$. DOl: 10.15562/ism.v11i1.555

\section{PENDAHULUAN}

Kejadian fraktur memiliki proporsi yang substansial dari total pasien yang datang ke unit gawat darurat rumah sakit. Mekanisme kecelakaan lalu lintas atau kecelakaan lainnya merupakan faktor utama dan sebagaian besar adalah patah pada tulang panjang terutama pada ekstremitas bawah. Tindakan pembedahan menjadi salah satu pilihan dalam penanganan fraktur. Walaupun dengan kemajuan teknik pembedahan, banyak komplikasi yang dapat terjadi baik akibat kondisi sebelum operasi ataupun akibat komplikasi dari tindakan operasi ekstremitas bawah. ${ }^{1}$

Operasi pada kasus orthopaedi khususnya pada fraktur ekstremitas bawah dengan pemasangan fiksasi internal memiliki resiko yang cukup besar untuk terjadinya thrombosis vena dalam (DVT). DVT merupakan keadaan terbentuknya thrombus di dalam sistem vena dalam dan dapat menyebabkan kondisi yang fatal berupa emboli paru. Hal ini dikarenakan proses operasi dengan diseksi jaringan dan kerusakan pembuluh darah yang luas serta imobilisasi paska operasi menyebabkan terganggunya aliran balik vena. ${ }^{1,2}$

Insiden terjadinya DVT yang asimptomatik setelah operasi besar orthopaedi tanpa profilaksis dilaporkan berkisar 30-80\%, sedangkan insiden DVT yang simptomatik dilaporkan berkisar 0,5-4\%. Diperkirakan 40-50\% dari DVT asimptomatik yang tidak ditangani akan menyebaban terjadinya emboli paru dalam 3 bulan dan 10\% dari emboli paru simptomatik akan menyebabkan kematian dalam 1 jam setelah serangan. Di Amerika Serikat, angka kejadian DVT berkisar 600.000 kasus tiap tahunnya, dan hampir 5.000 pasien meninggal sebagai akibat dari emboli paru. ${ }^{2}$ Oleh karena itu, sangatlah penting untuk menegakkan diagnosa DVT sehingga pencegahan dapat dilakukan serta kematian akibat emboli paru yang disebakan oleh DVT dapat dicegah.

Penegakan diagnosis DVT masih merupakan suatu tantangan. Pemeriksaan D-dimer adalah salah satu pemeriksaan untuk utama dalam penegakan diagnosis DVT. Pemeriksaan D-dimer tidak serta merta dapat digunakan untuk menegakkan diagnosis DVT, namun kadar D-dimer dapat digunakan sebagai prediktor terhadap resiko terjadinya DVT. $^{3}$ D-dimer merupakan hasil dari degradasi fibrin dan dipertimbangkan sebagai indikator fibrinolysis pada thrombosis intravaskular. Menurut penelitian yang dilakukan oleh Akihiro dkk (2009), kadar D-dimer lebih dari 7,2 $\mu \mathrm{g} / \mathrm{ml}$ memiliki resiko yang tinggi untuk terjadi suatu DVT. ${ }^{4}$ Pemeriksaan D-dimer dalam menetukan resiko DVT membutuhkan waktu yang cukup lama dan biaya yang cukup mahal. Secara klinis diketahui adanya suatu alternatif penentuan risiko DVT yakni salah satunya skor Skor Caprini. Skor Caprini merupakan suatu sistem penilaian sederhana yang dibuat oleh Caprini, bertujuan untuk menilai faktor resiko yang berhubungan dengan meningkatnya resiko terjadinya suatu DVT. ${ }^{5}$

Oleh karena, keterbatasan pemeriksaan D-dimer dalam menentukan resiko DVT maka perlu dicari hubungan antara kadar D-dimer dan Skor Caprini, serta mencari titik potong Skor Caprini dengan resiko kejadian DVT (kadar D-dimer $>7,2 \mathrm{ug} / \mathrm{ml}$ ) sebagai acuan resiko tinggi untuk terjadinya DVT.

\section{METODE}

Penelitian menggunakan rancangan cross-sectional analitik yang bertujuan umtuk mengetahui hubungan Skor Caprini dengan kadar D-dimer pada pasien paska fiksasi internal fraktur tulang panjang ekstremitas bawah. Sampel penelitian dikumpulkan secara konsekutif di Instalasi Rawat Inap RSUP Sanglah Denpasar dari periode bulan Desember 2018 sampai dengan Februari 2019. Kriteria inklusi pada penelitian ini yakni pasien dengan fraktur tulang panjang ekstremitas bawah yang dilakukan fiksasi internal (intramedullary nail atau plate dan screw) di Instalasi Bedah Sentral RSUP Sanglah Denpasar, penggunaan metode anestesi spinal dan/atau epidural selama operasi, usia di bawah 80 tahun, status fisik ASA 1 atau 2 dan bersedia mengikuti penelitian. Kriteria eksklusi pada penelitian ini diantaranya pasien yang belum menjalani terapi konservatif sesuai indikasi, riwayat DVT sebelumnya, trombositopenia, riwayat penyakit jantung atau pembuluh darah perifer dan stroke, riwayat konsumsi obat imunosupresif dan riwayat mendapatkan obat antikoagulan 48 jam sebelum dilakukan pemeriksaan. Data terkait demografi dan data klinis selama menjalani perawatan diperoleh melalui anamnesis dan data rekam medis. Pada seluruh sampel, dilakukan pemeriksaan kadar D-dimer pada sebelum operasi dan 24 jam paska tindakan operasi (random blood sampling). Pemeriksaan kadar D-dimer dilakukan 
di Laboratorium Patologi Klinik RSUP Sanglah Denpasar.

Data karakteristik pasien yang masuk ke dalam penelitian dilakukan analisis deskriptif. Uji normalitas data dilakukan dengan metode ShapiroWilk. Analisis bivariat dengan uji korelasi pearson bila data berdistribusi normal dan uji korelasi spearman jika tidak berdistribusi normal. Tingkat kemaknaan ( $\alpha$ ) penelitian ini ditetapkan $<0,05$. Analisis statistik dilakukan dengan menggunakan perangkat lunak IBM SPSS v22 pada sistem operasi Microsoft Windows.

\section{HASIL}

Penelitian ini melibatkan 30 pasien yang terdiri dari 19 laki-laki (63,33\%) dan 11 perempuan (36,67\%). Usia sampel memiliki rentang 21-94 tahun, dengan nilai tengah 59,6 tahun dan usia tersering (modus) adalah 73 tahun. Perdarahan durante op memiliki rentang 20-1000 cc, dengan nilai tengah $250 \mathrm{cc}$ dan nilai modus $100 \mathrm{cc}$ dan $500 \mathrm{cc}$. Pasien pada sampel penelitian ini mendapat transfusi dengan rentang 0-2 kantong. Nilai tengahnya adalah 0 kantong, dengan nilai tersering 0 kantong pada sebanyak 17 pasien (63\%). Terkait penilaian Skor Caprini, 3 orang sampel (10\%) mengalami multiple trauma dalam 1 bulan terakhir, 9 orang sampel (30\%) mengalami obesitas (IMT $>25 \mathrm{~kg} / \mathrm{m}^{2}$ ), 2 orang sampel $(6,7 \%)$ mendapat tindakan imobilisasi

Tabel 1 Distribusi Karakteristik Subjek Penelitian secara Umum

\begin{tabular}{lcc}
\hline & Karakteristik & Jumlah \\
\hline Jenis Kelamin & Laki-laki & $19(63,3 \%)$ \\
Usia & Perempuan & $11(36,7 \%)$ \\
Perdarahan & Rerata & 59,6 tahun $(21-94$ tahun $)$ \\
Komorbiditas & Rerata & $250 \mathrm{cc}(20-1000 \mathrm{cc})$ \\
& Multiple trauma & $3(10 \%)$ \\
& Obesitas & $9(30 \%)$ \\
& Plaster Cast Immobilization & $2(6,7 \%)$ \\
& PPOK & $1(3,3 \%)$ \\
& Tungkai bengkak & $2(6,7 \%)$ \\
\hline
\end{tabular}

Tabel 2 Data Deskriptif serta Uji Normalitas Skor Caprini dan D-dimer

\begin{tabular}{lcccc}
\hline Variabel & Rerata & $\begin{array}{c}\text { Rentang } \\
\text { (jangkauan) }\end{array}$ & $\begin{array}{c}\text { Shapiro-Wilk } \\
\text { (nilai } \boldsymbol{p} \text { ) }\end{array}$ & $\begin{array}{c}\text { Distribusi } \\
\text { Data }\end{array}$ \\
\hline Skor Caprini & 9,37 & $7-13$ & 0,114 & Normal \\
Delta D-Dimer & 5,23 & $0,56-12,28$ & 0,074 & Normal \\
D-Dimer Pre-Op & 6,59 & $2,50-13,20$ & 0,056 & Normal \\
D-Dimer Post-Op & 11,50 & $3,71-19,89$ & 0,432 & Normal \\
\hline
\end{tabular}

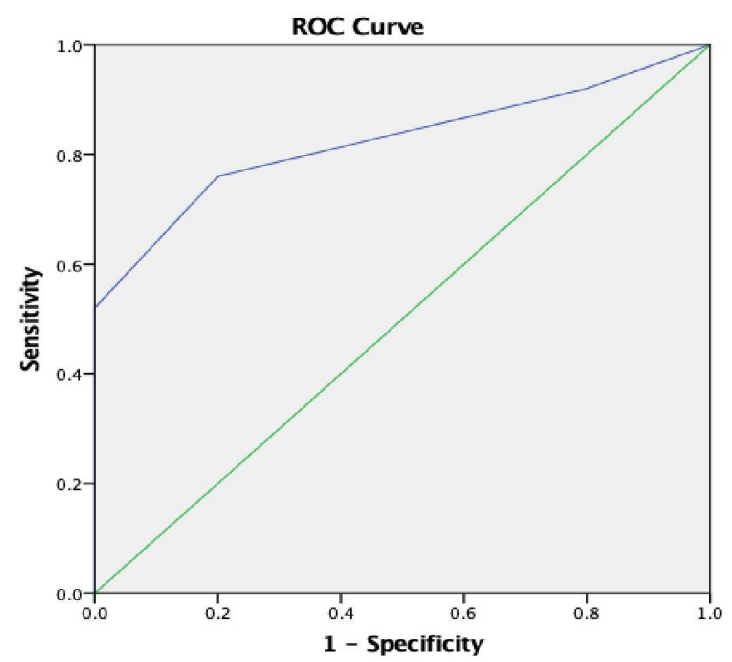

Gambar 1 Kurva ROC Skor Caprini dengan resiko terjadinya DVT (D-Dimer> $7 \mu \mathrm{g} / \mathrm{ml})$

plaster cast dalam 1 bulan terakhir, 1 orang sampel (3,33\%) mengalami PPOK, dan 2 orang $(6,7 \%)$ memiliki riwayat keluhan tungkai bengkak dalam beberapa hari terakhir. Rerata Skor Caprini sebesar 9,37 dengan rentang skor 7-13, rerata Delta D-dimer sebesar 5,23 dengan rentang nilai 0,56-12,28, rerata D-dimer pre-op sebesar 6,59 dengan rentang nilai 2,50-13,20, dan rerata D-dimer post-op sebesar 11,50 dengan rentang nilai 3,71-19,89. Semua variabel data berdistribusi normal berdasarkan uji Shapiro-Wilk.

Analisis inferensial korelasi Pearson dilakukan untuk generalisasi hasil penelitian. Uji linearitas untuk sebagai prasyarat dalam analisis korelasi atau regresi linear menghasilkan nilai $\mathrm{F}=1,115$ dan nilai $\mathrm{p}=0,380$, dengan demikian hubungan antara Skor Caprini dan D-dimer bersifat linear. Analisis dilanjutkan dengan uji korelasi Pearson untuk menilai kekuatan dan arah hubungan linier dari kedua variabel. Hasil uji korelasi pearson menghasilkan nilai $r=0,726$ dan nilai $p \leq 0,0001$. Berdasarkan hasil tersebut, maka secara statistik terdapat korelasi positif antara Skor Caprini dan D-dimer. Untuk mengetahui titik potong (Cut-off point) dari Skor Caprini yang setara dengan resiko tinggi terjadinya DVT dari prediksi D-dimer $(>7,2 \mu \mathrm{g} / \mathrm{ml})$ menurut Akihiro, ${ }^{4}$ maka dilakukan anlisis kurva ROC (Gambar 1). Area Under Curve (AUC) dari metode kurva ROC ditemukan sebesar 0,824 $(95 \%$ CI 0,669-0,979) dengan nilai $p=0,024$. Secara Statistik, nilai AUC sebesar 82,4\% tergolong baik. Nilai optimal dari titik potong ditentukan melalui nilai sensitifitas dan spesifitas dengan Index Youden. Titik potong optimal ditemukan pada skor Caprini 8, dimana bila skor melebihi 8 maka risiko DVT setara dengan prediksi dengan $\mathrm{D}$-dimer paska operasi lebih dari $7,2 \mu \mathrm{g} / \mathrm{ml}$. 


\section{PEMBAHASAN}

Terdapat beberapa faktor yang dapat menjelaskan pathogenesis dari DVT terutama berkaitan dengan "Virchow's Triad" yaitu hypercoagulability, endothelial injury, dan venous stasis. ${ }^{6}$ Untuk kasus fraktur tulang panjang ekstremitas bawah ditemukan cedera endotel baik akibat trauma langsung maupun faktor mekanik akibat prosedur operasi. Fiksasi internal pada tulang panjang ekstremitas bawah merupakan suatu tindakan yang membutuhkan diseksi jaringan yang luas. Dengan semakin luasnya jaringan lunak yang rusak, maka semakin banyak pula pembuluh darah besar dan kecil yang rusak. Selain itu, nyeri paska operasi menyebabkan pasien untuk menunda pergerakan tungkai yang berakibat stasis dari aliran darah vena. Jumlah perdarahan yang banyak intra operatif juga dapat menyebabkan gangguan keseimbangan pembekuan darah akibat dari hilang atau berkurangnya faktor faktor yang dibutuhkan dalam proses pembekuan maupun degradasi trombus. ${ }^{7,8}$ Ketiga faktor tersebut saling terkait dan menyebabkan meningkatnya resiko terbentuknya trombus pada sistem vena salah satunya DVT.

D-dimer adalah produk akhir degenerasi ikatan silang fibrin oleh aktivitas kerja plasmin dalam sistem fibrinolitik. ${ }^{7,8}$ Sejak tahun 1990, pemeriksaan D-dimer bermanfaat untuk mengetahui adanya pembentukan bekuan darah yang abnormal atau proses trombotik (indirek) dan untuk mengetahui adanya lisis bekuan atau proses fibrinolitik (direk). Hasil pemeriksaan kadar D-dimer memiliki nilai sensitifitas dan nilai prediktif negatif yang tinggi untuk dua keadaan tersebut, serta bersifat minimal invasif karena sampel diambil dari darah perifer. Kadar D-dimer telah terbukti sebagai prediktor yang akurat dalam memperkirakan sebuah kejadian thrombosis vena. Dimana kenaikan kadar D-dimer dapat menunjukkan peningkatan risiko terjadinya komplikasi DVT, dan akurasi kadar D-dimer dalam memprediksi kejadian DVT mencapai 98\% dibandingkan dengan standar baku pemeriksaan yaitu doppler. ${ }^{1}$ Beberapa penelitian telah menunjukkan D-dimer memiliki karakteristik penanda yang sensitif tetapi tidak spesifik untuk DVT. ${ }^{7-9}$ Hasil pemeriksaan yang positif menunjukkan adanya trombus, namun tidak dapat menunjukkan lokasi kelainan dan menyingkirkan etiologi-etiologi potensial lain. ${ }^{7,8}$

Pada penelitian ini diperoleh kadar D-dimer yang tinggi saat 24 jam paska operasi pada pasien dengan fraktur tulang panjang pada ekstremitas bawah yang telah dilakukan fiksasi internal dengan intramedullary nail atau plate and screw dengan nilai delta $\mathrm{D}$-dimer sebesar 5,23 $\mu \mathrm{g} / \mathrm{ml}$ dengan rentang nilai $0,56-12,28 \mu \mathrm{g} / \mathrm{ml}$,
D-dimer sebelum operasi sebesar $6,59 \mu \mathrm{g} / \mathrm{ml}$ dengan rentang nilai 2,50-13,20 $\mu \mathrm{g} / \mathrm{ml}$, dan D-dimer paska operasi sebesar $11,50 \mu \mathrm{g} / \mathrm{ml}$ dengan rentang nilai 3,71-19,89 $\mu \mathrm{g} / \mathrm{ml}$. Hasil penelitian ini juga bersesuaian dengan penelitian yang dilakukan oleh Naeem dkk dimana disebutkan bahwa terjadi peningkatan D-dimer yang signifikan pada 24 jam paska operasi. ${ }^{10}$ Penelitian lain oleh Hooman dkk menyebutkan bahwa terjadi peningkatan konsentrasi D-dimer yang signifikan segera setelah operasi dengan nilai $\mathrm{D}$-dimer $1800 \mathrm{ng} / \mathrm{ml}$ dan menurun menjadi $480 \mathrm{ng} / \mathrm{ml}$ seteal 7 hari paska operasi. Hooman juga menyimpulkan bahwa pemeriksaan D-dimer cukup memberikan tingkat akurasi yang adekuat dalam mendiagnosis DVT. ${ }^{11}$

Skor Caprini pada sisi lain, merupakan suatu sistem penilaian yang bertujuan untuk menilai faktor resiko yang berhubungan dengan meningkatnya resiko terjadinya suatu DVT. ${ }^{5}$ Skor Caprini adalah suatu skoring sederhana yang dapat dinilai dalam 24 jam sejak trauma terjadi. ${ }^{12}$ Pada penelitian ini diperoleh nilai Skor Caprini yang tinggi saat 24 jam paska operasi pada ekstremitas bawah (intramedullary nail atau plate and screw) dengan nilai rerata sebesar 9,37. Uji korelasi diperoleh hasil yang menenunjukkan hubungan positif kuat antara Skor Caprini dengan kadar D-dimer (nilai $r=0,726$ dan nilai $p \leq 0,0001$ ). Pada penelitian yang dilakukan Eric pada tahun 2016, diperoleh Skor Caprini lebih dari 5 poin pada lebih dari 3 jam paska operasi pada pasien dengan fraktur panggul (hip fracture), pelvis dan femur. ${ }^{13}$ Hasil yang mendukung penggunaan Skor Caprini juga berasal dari penelitian Kitchai dkk. Pada penelitiannya disebutkan tingkat sensitivitas dan spesifisitas dari Skor Caprini $>12$ adalah 93\% dan 35\%, untuk Skor Caprini >13 adalah 60\% dan $73 \%$ secara berturut-turut. ${ }^{14}$ Kitchai dkk menyimpulkan Skor Caprini dengan poin 12 ditambah dengan pemeriksaan USG Doppler yang positif memberikan tingkat akurasi yang adekuat dalam mendiagnosa DVT pada kasus fraktur panggul. Jika Skor Caprini kurang dari 12 maka dibutuhkan pemeriksaan USG untuk memperkuat diagnosis DVT. ${ }^{14}$ Hal serupa juga disebutkan oleh Haixia dkk, dimana penelitiannya menemukan peningkatan Skor Caprini yang signifikan dibandingkan dengan kelompok control yang tidak beresiko DVT dimana memperkuat hipotesis bahwa ada hubungan yang adekuat antara peningkatan Skor Caprini dengan tingkat kejadian DVT. ${ }^{15}$

\section{SIMPULAN}

Terdapat hubungan positif antara Skor Caprini dan D-Dimer dengan Cut-off point Skor Caprini pada 
nilai 8 setara dengan $\mathrm{D}$-dimer $>7,2 \mathrm{ug} / \mathrm{ml}$ sebagai prediktor risiko DVT pada pasien paska fiksasi internal fraktur tulang panjang ekstremitas bawah.

\section{KONFLIK KEPENTINGAN}

Tidak ada.

\section{ETIKA PENELITIAN}

Penelitian ini telah mendapat persetujuan etik oleh Komisi Etik, Fakultas Kedokteran Universitas Udayana/RSUP Sanglah Denpasar, Bali, Indonesia sebelum penelitian berjalan.

\section{PENDANAAN}

Penulis bertanggung jawab terhadap pendanaan penelitian ini tanpa melibatkan pihak sponsor, beasiswa, ataupun sumber pendanaan lainnya.

\section{KONTRIBUSI PENULIS}

Seluruh penulis berkontribusi terhadap penelitian ini baik dari perencaan proposal penelitian, pencarian data, analisis data penelitian, hingga interpretasi dan penyusunan naskah publikasi.

\section{DAFTAR PUSTAKA}

1. Miller M.D., Thompson S.R. Miller's review of orthopaedics 7th. 2015. $891 \mathrm{p}$.

2. Lee S.Y., Ro D.H., Chung C.Y., Lee K.M., Kwon S.-S., Sung K.H., et al. Incidence of Deep Vein Thrombosis after Major Lower Limb Orthopedic Surgery: Analysis of a Nationwide Claim Registry. Yonsei Med J. 2015;56(1):139.

3. Gearhart M.M., Luchette F.A., Proctor M.C., Lutomski D.M., Witsken C., James L., et al. The risk assessment profile score identifies trauma patients at risk for deep vein thrombosis. Surgery. 2000;128(4):631-40.

4. Sudo A., Wada H., Nobori T., Yamada N., Ito M., Niimi R., et al. Cut-off values of D-dimer and soluble fibrin for prediction of deep vein thrombosis after orthopaedic surgery. Int J Hematol. 2009;89(5):572-6.
5. Caprini J.A. Thrombosis Risk Assessment as a Guide to Quality Patient Care. Disease-a-Month. 2005;51(2-3):70-8.

6. Magetsari R., Dewo P., Nugroho A.S., Lanodiyu Z. Deep Vein Thrombosis in Elderly Patients following Surgery for Fracture of the Proximal Femur. Malaysian Orthop J. 2014;8(3):7-10.

7. Barber M., Langhorne P., Rumley A., Lowe G.D.O., Stott D.J. d -Dimer Predicts Early Clinical Progression in Ischemic Stroke. Stroke. 2006;37(4):1113-5.

8. Laffan M., Manning R. Investigation of a thrombotic tendency [Internet]. Dacie and Lewis Practical Haematology. Elsevier; 2006. p. 441-63.

9. Noordin S., McEwen J.A., Kragh C.J.F., Eisen A., Masri B.A. Surgical Tourniquets in Orthopaedics. J Bone Jt SurgeryAmerican Vol. 2009;91(12):2958-67.

10. Naeem M.A., Usman M., Latif M.K., Aamir M. The relationship of D-dimer levels with risk for developing deep-vein thrombosis and/or pulmonary thromboembolism after orthopaedic trauma surgery. J Ayub Med Coll Abbottabad. 21(2):113-6.

11. Bakhshi H., Alavi-Moghaddam M., Wu K.C., Imami M., Banasiri M. D-dimer as an applicable test for detection of posttraumatic deep vein thrombosis in lower limb fracture. Am J Orthop (Belle Mead NJ). 2012;41(6):E78-80.

12. Grant P.J., Greene M.T., Chopra V., Bernstein S.J., Hofer T.P., Flanders S.A. Assessing the Caprini Score for Risk Assessment of Venous Thromboembolism in Hospitalized Medical Patients. Am J Med. 2015/11/06. 2016;129(5):528-35.

13. Swanson E. Caprini Scores, Risk Stratification, and Rivaroxaban in Plastic Surgery: Time to Reconsider Our Strategy. Plast Reconstr surgery Glob open. 2016;4(6):e733.

14. Luksameearunothai K., Sa-Ngasoongsong P., Kulachote N., Thamyongkit S., Fuangfa P., Chanplakorn P., et al. Usefulness of clinical predictors for preoperative screening of deep vein thrombosis in hip fractures. $B M C$ Musculoskelet Disord. 2017;18(1):208.

15. Zhou H., Hu Y., Li X., Wang L., Wang M., Xiao J., et al. Assessment of the Risk of Venous Thromboembolism in Medical Inpatients using the Padua Prediction Score and Caprini Risk Assessment Model. J Atheroscler Thromb. 2018;25(11):1091-104.

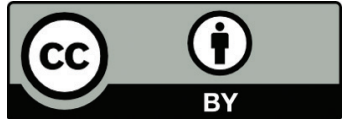

This work is licensed under a Creative Commons Attribution 